\title{
A Non-Pathogenic Environmental Isolate of Pseudomonas aeruginosa MCCB 123 with Biotechnological Potential
}

\author{
Divya Jose, A. Mohandas and I.S. Bright Singh*
}

National Centre for Aquatic Animal Health, Cochin University of Science and Technology, Lakeside Campus, Fine Arts Avenue, Cochin - 682016, India

*Corresponding author

A B S T R A C T

\begin{tabular}{|l|}
\hline Ke y w o r d $\mathbf{s}$ \\
$\begin{array}{l}\text { Pseudomonas } \\
\text { aeruginosa, } \beta-1,3 \\
\text { glucanase, LasA } \\
\text { protease, LasB } \\
\text { protease, } \\
\text { biotechnology }\end{array}$ \\
\hline Article Info \\
\hline $\begin{array}{l}\text { Accepted: } \\
\text { 26 December } 2017 \\
\text { Available Online: } \\
\text { 10 January } 2018\end{array}$ \\
\hline
\end{tabular}

Pseudomonas aeruginosa MCCB 123 is a potent producer of enzymes such as $\beta-1,3$ glucanase, LasA and LasB proteases, which have been identified to have greater significance in the biotechnology sector. However, pathogenicity assessment of bacteria is essential for its industrial survival. Pathogenicity was assessed by a panel of virulence assays such as the presence of type III secretion toxin genes, motility assays, biofilm formation, adhesion and invasion assays on Hep- 2 and HeLa monolayers and antibiogram profiling. Analysis of the major cytotoxic exoU gene revealed the absence of the gene, thus confirms the non-cytotoxic phenotype of the bacterium. $P$. aeruginosa exhibited three types of motilities viz., swimming, swarming and twitching motilities and proved to be a moderate biofilm producer with a 3.10 \pm 0.52 -fold increase in the optical density at $\mathrm{Abs}_{570}$ when compared to control. Antibiogram suggested the possibility of antibiotic treatment as an effective method for eradication of its biofilm. The non-pathogenic nature of the bacterium suggests industrially viability of this organism for the production of biotechnological relevant enzymes.

\section{Introduction}

Pseudomonas aeruginosa is bacterium that is ubiquitously distributed in aquatic habitats and soil and is a normal bacterial flora of intestine, mouth and skin. The colonization is normally harmless and infection occurs only when general or local defence mechanism is reduced (Kiewitz and Tummler, 2000). i.e., it is an opportunistic human pathogen (Lyczak, 2000 and Ortiz-Herrera, 2004). It is frequently isolated from hospital environments, clinical specimens and soil and water environments (Palleroni, 1992). As several members of $P$. aeruginosa are known human pathogens, it is pertinent to differentiate between pathogenic and non-pathogenic strains.

Environmental isolates of $P$. aeruginosa can be found in soils, surface and ground water and the number of living cells in the soil does not reach the level of infection risk (Atzel et al., 2008). Clinical bacterial isolates are believed to be pathogenic when compared to environmental counterparts. The major reason for its emergence as a pathogen is due to its intrinsic resistance to antibiotics and disinfectants (Senthil et al., 2011). 
The bacterium Pseudomonas aeruginosa MCCB 123 used in the present study was an environmental isolate isolated from coir retting ground of Chellanum, kerala, India. The organism was found to be potent producer of relevant industrial enzymes such as $\beta-1,3$ glucanase (Jose et al., 2014) LasA protease (Jose et al., 2017) and LasB proteases (Jose et al., 2017). However, assessment of pathogenicity of this enzyme producer strain is essential for its industrial survival. Therefore, an evaluation has been made on the pathogenicity of this bacterium for its industrial acceptance.

\section{Materials and Methods}

\section{Identification of bacterial isolate}

The bacterial isolate was identified by phenotypic characterization followed by molecular characterization by way of $16 \mathrm{~S}$ rRNA gene sequencing. Amplification of $16 \mathrm{~S}$ rRNA gene was performed using universal primers $16 \mathrm{~S} 1$ (GAG TTT GAT CCT GGC TCA) and 16 S2 (ACG GCT ACC TTG TTA CGA CTT). The amplified PCR product of 16S rRNA was purified using QIAEX II gel purification kit (Qiagen) and was used for cloning into pGEM-T Easy vector (Promega, USA) and sequenced using ABI PRISM 3700 Big Dye Sequencer at Microsynth AG, Switzerland.

\section{Assessment of pathogenicity}

\section{Detection of type III toxin genes (exoU and exoS) by PCR}

Genomic DNA of the bacterium was extracted by phenol-chlorofom method (Sambrook and Russell, 2001) as described above. PCR amplification of exoU and exoS gene was carried out using the primers as described by Zhu et al., (2006). A 428-bp fragment of the exoU gene was amplified using primers exoU
(F) (5'-GGG AAT ACT TTC CGG GAA GTT-3') and exoU (R) (5' -CGA TCT CGC TGC TAA TGT GTT-3'). A 1352-bp fragment of the exoS gene was amplified using primers $\operatorname{exoS}(\mathrm{F})\left(5^{\prime}\right.$-ATC GCT TCA GCA GAG TCC GTC-3') and exoS (R) (5' -CAG GCC AGA TCA AGG CCG CGC-3’).

Reaction mixture (final volume $25 \mu \mathrm{l}$ ) contained $2.5 \mu 110 \mathrm{X}$ buffer, $1 \mu 110 \mathrm{pmol}$ each of oligonucleotide primer, $1 \mu 1$ DNA template, $2.5 \mu 12.5 \mathrm{mM}$ each deoxynucleoside triphosphate, $1 \mu \mathrm{l}$ Taq polymerase, and the remaining volume made up with sterile Milli Q water. The amplification profile consisted of initial denaturation at $94^{\circ} \mathrm{C}$ for $2 \mathrm{~min}$ followed by 30 cycles of annealing of primers for $30 \mathrm{~s}$ at $59^{\circ} \mathrm{C}$ for exoU and $68^{\circ} \mathrm{C}$ for exoS and primer extension at $72^{\circ} \mathrm{C}$ for $1.5 \mathrm{mi}$. The PCR product was separated on $1 \%$ agarose gel.

\section{Swimming motility}

Swimming motility was done according to the method of Deligianni et al., (2010). Swim plates were prepared by using $1 \%$ tryptone, $0.5 \mathrm{NaCl}, 0.3 \%(\mathrm{w} / \mathrm{v})$ agar. The plates were inoculated with the bacterium using a sterile tooth pick and incubated overnight at $37^{\circ} \mathrm{C}$. The ability to swim was assessed by the radius of the colony. The swimming zones were measured after $48 \mathrm{~h}$ incubation at $37^{\circ} \mathrm{C}$. The experiments were conducted in triplicates.

\section{Swarming motility}

Swarming motility was done according to Deligianni et al., (2010). The medium used consisted of $0.5 \%$ nutrient broth, $0.5 \%$ glucose and $0.5 \%$ agar.

Plates were inoculated with a $5 \mu 1$ aliquot from an overnight culture of the bacterium in LB broth on the top of the agar and incubated at $37^{\circ} \mathrm{C}$ for $48 \mathrm{~h}$. 


\section{Twitching motility}

Twitching motility was done according to Head and Yu (2004). Freshly prepared and briefly dried twitch plates (Tryptic soy broth solidified with $1 \%(\mathrm{w} / \mathrm{v})$ Difco granulated agar) were stab inoculated with a sharp toothpick into the bottom of the Petri dish.

After incubation at $37^{\circ} \mathrm{C}$ for $24 \mathrm{~h}$, the agar was removed from the twitching activity plate and the plate was stained with $0.25 \% \quad(w / v)$ Commassie blue for 30 minutes. The stain was removed and the twitching activity was measured in centimetres.

\section{Ability to form Biofilm}

Biofilm assay was performed according to Head and $\mathrm{Yu}$ (2004). Overnight cultures of the bacterium was diluted 1:100 in fresh LB medium, dispensed $125 \mu \mathrm{l}$ to the wells of a 96-well micro titre plate and grown for $15 \mathrm{~h}$ at $37^{\circ} \mathrm{C}$ without aeration.

After incubation, the wells were stained with $100 \mu \mathrm{l}$ of $0.25 \%$ crystal violet for $30 \mathrm{~min}$ at $25^{\circ} \mathrm{C}$. Stain was discarded and the plate was rinsed three to five times in standing water and allowed to dry. Stained biofilm was solubilised with $200 \mu 1$ of $95 \%$ ethanol for 10 min and the optical density was read at 570 $\mathrm{nm}$. Assays were done triplicates. A suitable control (LB medium without inoculation) was also kept.

Biofilms were classified according to the method of Stepanovic et al., (2000). When there was no increase of optical density over control, it was considered as a non-biofilm producer. Meanwhile, up to a 2-fold increase in optical density was considered as a weak producer, up to 4-fold increase in optical density as moderate producer and greater than 4-fold increase in optical density as strong producer.

\section{Adhesion and invasion assay on Hep-2 and HeLa monolayers}

Adherence and invasion assays were carried out by the modified method of Prasad et al., (1996). An $18 \mathrm{~h}$ old culture of the bacterium was centrifuged at $10,000 \mathrm{~g}$ for $15 \mathrm{~min}$ at $4^{\circ} \mathrm{C}$. The bacterial pellet was re-suspended in MEM with $10 \% \mathrm{FBS}$ and the inoculum was adjusted to $10^{7} \mathrm{CFU} / \mathrm{ml}$.

Hep-2 and HeLa cells were grown to confluence in 24-well plate using Minimal Essential Medium (MEM) containing 10\% FBS at $37^{\circ} \mathrm{C}$ in $95 \%$ air and $5 \% \mathrm{CO}_{2}$. The monolayers were inoculated with $200 \mu 1$ bacterial suspension in triplicate wells. In to the other set of triplicate wells, gentamicin $\left(200 \mu \mathrm{g} \mathrm{ml}^{-1}\right)$ was added. The plate was incubated for $3 \mathrm{~h}$ at $37^{\circ} \mathrm{C}$ in $95 \%$ air and $5 \%$ $\mathrm{CO}_{2}$. In to the first set of triplicate wells antibiotic was not added in order to enumerate the number of bacteria that have adhered and invaded the cell lines. All the wells were washed with sterile MEM with 10\% FBS to remove un-adhered bacterial cells. The monolayers were lysed with $0.01 \%$ Triton X100.

The lysed monolayer suspensions were then serially diluted $\left(10^{-1}\right.$ to $\left.10^{-6}\right)$ and $100 \mu 1$ of each suspension were plated on LB agar and incubated at $37^{\circ} \mathrm{C}$ for $24 \mathrm{~h}$. The viable count was determined as colony forming units (CFU) on the plates multiplied by its dilution factor. Viable bacteria recovered from the wells with gentamicin were considered intracellular (those which invaded the cells) and bacteria recovered from the wells without gentamicin were considered as the extracellular + intracellular. The adherence was calculated by the formulae: (CFU/ml from well without gentamicin at particular dilution $\mathrm{CFU} / \mathrm{ml}$ from the well with gentamicin at the same dilution) $\times$ dilution factor). The assays were carried out in triplicates. 


\section{Antibiotic susceptibility testing}

Antimicrobial susceptibility of the bacterium was determined according to the modified disk diffusion method of Zhu et al., (2006). The bacterial culture was adjusted to $10^{7} \mathrm{CFU} / \mathrm{ml}$ (equivalent to a $0.5 \mathrm{McFarland}$ standard) and was plated onto Muller-Hinton agar. The plates were allowed to dry for $5 \mathrm{~min}$ and not more than 6 antibiotic discs (Himedia) were applied on each agar plate and were then incubated at $37^{\circ} \mathrm{C}$ for $18 \mathrm{~h}$. The zone of bacterial inhibition was examined by measuring the annular radius after incubation.

The organism was considered as susceptible, reduced susceptible or resistant to a particular antibiotic on the basis of the diameters of the inhibition zones that matched the criteria of the manufacturer's interpretive table, which followed the recommendations of the Clinical and Laboratory Standards Institute (CLSI, 2007).

\section{Results and Discussion}

\section{Identification of the bacterial isolate}

\section{Phenotypic identification}

The cells appeared as Gram negative short rods. The isolate was motile, oxidase positive, produced diffusible greenish pyocyanin pigment, have denitrification activity and capable of growing at $41^{\circ} \mathrm{C}$. Moreover, Pseudomonas MCCB 123 produced acid from xylose and mannose and was positive for the utilization of glucose and sucrose as a sole carbon source for its growth.

It was positive for gelatin, starch, casein hydrolysis. The characteristics considered have been detailed in Table 1. The phenotypic characteristics were suggestive of the bacterium as Pseudomonas aeruginosa, according to Baumann and Schubert (1984).

\section{Molecular identification by $16 S$ rRNA gene sequencing}

DNA amplified using universal primers of $16 \mathrm{~S}$ rRNA gene primers, cloned into pGEM-T easy Vector partially sequenced using $\mathrm{T} 7$ and SP6 vector primers. When the sequence was compared with the GenBank data base using available from NCBI (www.ncbi.nlm. nih.gov), it showed $100 \%$ query coverage with 16SrRNA gene sequence of Pseudomonas aeruginosa. The sequence is deposited in the GenBank with the accession number FJ665510.

\section{Assessment of pathogenicity of P.aeruginosa MCCB 123}

\section{Analysis of type III secretion toxin genes}

Analysis of the presence of type III secretion toxin encoding genes revealed that $P$. aeruginosa MCCB 123 did not harbour exoU gene, while a positive amplification with an amplicon of $1352 \mathrm{bp}$ was obtained for exoS gene (Fig. 1).

\section{Motility assays}

P. aeruginosa MCCB 123 exhibited swimming and swarming motilities with distance of the migration of $1.46 \pm 0.05 \mathrm{~cm}$ and $1.53 \pm 0.11 \mathrm{~cm}$ radius, respectively, from the inoculation point. The twitching motility was distinguished by the presence of twitch zone formed by colony expansion with a zone diameter of $3.4 \pm 0.17 \mathrm{~cm}$. The results are shown in Table 2.

\section{Biofilm formation}

P. aeruginosa MCCB 123 is considered as a moderate biofilm producer with $3.10 \pm 0.52$ fold increase in the optical density when compared to control (LB medium without inoculation) at $\mathrm{Abs}_{570}$ (Table 3). 
Table.1 Phenotypic characterisation of Pseudomonas aeruginosa MCCB 123

\begin{tabular}{|c|c|}
\hline Tests & Results \\
\hline Motility & motile \\
\hline Grams stain & gram negative rods \\
\hline Oxidase & positive \\
\hline Citrate utilization & positive \\
\hline Agrinine dihydrolase & positive \\
\hline Denitrification & negative \\
\hline Starch hydrolysis & positive \\
\hline Gelatin hydrolysis & Positive \\
\hline Casein hydrolysis & positive \\
\hline Lecithinase & positive \\
\hline Production of pyocyanin & positive \\
\hline Growth at $41^{\circ} \mathrm{C}$ & positive \\
\hline \multicolumn{2}{|l|}{ Utilisation of: } \\
\hline Glucose & positive \\
\hline Trehalose & negative \\
\hline Sucrose & positive \\
\hline \multicolumn{2}{|l|}{ Acid production from: } \\
\hline D(-) Ribose & negative \\
\hline D(-) Xylose & positive \\
\hline L(+) Arabinose & negative \\
\hline D(-)Sorbitol & negative \\
\hline Mannose & positive \\
\hline Rhamnose & negative \\
\hline Lactose & negative \\
\hline Sucrose & negative \\
\hline Trehalose & negative \\
\hline Adonitol & negative \\
\hline
\end{tabular}


Table.2 Motility assays of Pseudomonas aeruginosa MCCB 123

\section{Type of motility}

Swimming motility

Swarming motility

Twitching motility
Distance migrated (cm)

$1.46 \pm 0.05$

$1.53 \pm 0.11$

$3.4 \pm 0.17$

Table.3 Biofilm assay of Pseudomonas aeruginosa MCCB 123

\begin{tabular}{lcc}
\hline Test Abs 570 & Control Abs570 & Test Abs 570/ Control Abs570 \\
$1.72 \pm 0.28$ & $0.55 \pm 0.003$ & $3.10 \pm 0.52$ \\
\hline
\end{tabular}

Table.4 Adherence and Invasion assay of Pseudomonas aeruginosa MCCB 123 on Hep-2 and HeLa cell lines

Adherence assay

Hep-2

HeLa

Hep-2

HeLa

$\mathrm{O}(\mathrm{CFU} / \mathrm{ml})$

$\mathrm{O}(\mathrm{CFU} / \mathrm{ml})$

O (CFU/ml)

$\mathrm{O}(\mathrm{CFU} / \mathrm{ml})$

Table.5 Antibiogram of Pseudomonas aeruginosa MCCB 123

\begin{tabular}{|c|c|c|c|}
\hline Antibiotics & Disk content & Zone diameter & Inference \\
\hline \multicolumn{4}{|l|}{ Pencillins } \\
\hline Carbenicillin & $100 \mu \mathrm{g}$ & 23 & 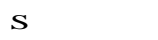 \\
\hline Piperacillin & $100 \mu \mathrm{g}$ & 15 & $\mathbf{R}$ \\
\hline Ticarcillin & $75 \mu \mathrm{g}$ & 16 & $\mathrm{~S}$ \\
\hline \multicolumn{4}{|l|}{ Cephalosporins } \\
\hline Ceftazidime & $30 \mu \mathrm{g}$ & 21 & $\mathrm{~s}$ \\
\hline Cefoperazone & $75 \mu \mathrm{g}$ & 21 & $\mathrm{~s}$ \\
\hline Cefotaxime & $30 \mu \mathrm{g}$ & 21 & $\mathbf{I}$ \\
\hline Ceftizoxime & $30 \mu \mathrm{g}$ & 15 & $\mathbf{I}$ \\
\hline \multicolumn{4}{|l|}{ Carbapenems } \\
\hline Imipenem & $10 \mu \mathrm{g}$ & 32 & $\mathrm{~s}$ \\
\hline \multicolumn{4}{|l|}{ Polymyxin } \\
\hline Colistin & $10 \mu \mathrm{g}$ & 11 & $\mathrm{~s}$ \\
\hline \multicolumn{4}{|c|}{ Aminoglycosides } \\
\hline Gentamicin & $10 \mu \mathrm{g}$ & 21 & $\mathrm{~s}$ \\
\hline Amikacin & $10 \mu \mathrm{g}$ & 17 & $\mathrm{~s}$ \\
\hline Tobramycin & $10 \mu \mathrm{g}$ & 22 & 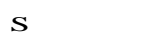 \\
\hline Netilmicin & $30 \mu \mathrm{g}$ & 16 & $\mathrm{~s}$ \\
\hline \multicolumn{4}{|c|}{ Fluroquinolones } \\
\hline Lomefloxacin & $10 \mu \mathrm{g}$ & 28 & $\mathrm{~s}$ \\
\hline Ofloxacin & $5 \mu \mathrm{g}$ & 28 & $\mathrm{~s}$ \\
\hline Norfloxacin & $10 \mu \mathrm{g}$ & 24 & $\mathrm{~s}$ \\
\hline S:Sensitive & R: Resistant & I:Intermediate & \\
\hline
\end{tabular}


Fig.1 Analysis of type III secretory toxin genes of $P$. aeruginosa MCCB 123. Lane1, $1 \mathrm{~kb}$ DNA ladder; lane 2, shows the absence of exoU gene of the P. aeruginosa MCCB 123, lane 3, amplification of $1352 \mathrm{bp}$ of exoS gene of $P$. aeruginosa MCCB 123

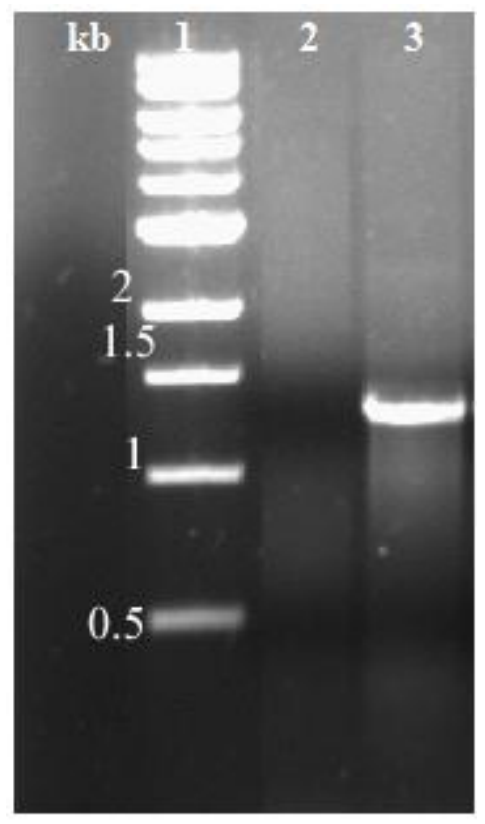

\section{Adhesion and Invasion assay on epithelial cell lines}

The capability of $P$. aeruginosa MCCB 123 to invade and adhere human epithelial cell lines (Hep-2 and HeLa) was assessed by gentamicin survival assays and the strain $P$. aeruginosa MCCB 123 was found to be nonadherent and also is not capable of invading into the human epithelial cell lines (Table 4).

\section{Antibiogram}

The susceptibility of $P$. aeruginosa MCCB 123 to 16 antibiotics belonging to six categories such as pencillins, cephems, carbapenems, lipopeptides, aminoglycosides and fluroquinolones was examined and listed in Table 5. Out of the 16 antibiotics belonging to six classes, the strain was sensitive to 13 antibiotics, resistant to one antibiotic (piperacillin) and intermediately sensitive to two antibiotics (cefotaxime and ceftizoxime). Confirmation of the pathogenicity of the producer isolate is important for its industrial acceptance. Pathogenicity of $P$. aeruginosa MCCB 123 was assessed by a panel of virulence assays like the presence of type III secretion toxin genes, motility assays, ability to form biofilm, adhesion and invasion on human epithelial cell lines and antibiotic resistance profiles.

One of the virulence determinants of $P$. aeruginosa is the presence of type III secretion toxin genes such as exoU, exoS, exo $T$ and exoY (Zhu et al., 2006). Analysis of the important type III toxin encoding genes, exoU and exoS can confirm the cytotoxic and invasiveness of $P$. aeruginosa (Choy et al., 2008). Those strains that harbour exoU gene are considered as cytotoxic phenotype and those that harbour exoS are considered as invasive phenotype, and strains that neither harbour exoU and exoS genes are considered as neither cytotoxic nor invasive (Zhu et al., 2006). The cytotoxicity of the non-invasive strains of $P$. aeruginosa are mainly due to the 
action of exoU gene (Hauser et al., 2002). Secretion of exoU has been regarded as a marker for high virulent strains of $P$. aeruginosa isolated from the infection, but exoS was not consistently associated with increased virulence (Schulert et al., 2003). The reason for exoS positive strains being associated with lower virulence may be attributed to the poor expression of exoS phenotypes in these isolates and such isolates are phenotypically classified as "neither invasive or nor cytotoxic" (Zhu et al., 2002). Analysis of type III toxin genes in $P$. aeruginosa MCCB 123 showed the presence of exoS gene, while exoU gene, a major contributor to the potential pathogenesis of $P$. aeruginosa (Lin H-H et al., 2006) was not detected. exoU has been previously shown to play a major role in mediating a cytotoxic phenotype of $P$. aeruginosa against lung epithelial cells and HeLa cells (Zaborina et al., 2006). The absence of exoU gene in $P$. aeruginosa MCCB 123 confirms the noncytotoxic phenotype on the strain, while the presence of exoS gene shows the invasive phenotype. Even though, $P$. aeruginosa MCCB 123 carry the gene for invasive phenotype (exoS gene), it is neither capable of adhesion nor invasion on both the epithelial cell lines tested. This may be due to the absence of effector protein $($ exo $S)$ responsible for invasion. The presence of the exoS gene and the absence of exoU gene in $P$. aeruginosa MCCB 123 suggest the genetic differences between the environmental isolate and the other clinical isolates (Kaszab et al., 2011). Zaborina et al., (2006) demonstrated that most of the multi-drug resistant clinical isolates of $P$. aeruginosa with barrier disruptive phenotypes harboured exoU gene and displayed cytotoxicity against Caco-2 monolayers. However, clinical isolates that harboured exoS gene were not cytotoxic to Caco-2 cells. Fleiszig et al., (1997), screened clinical isolates of $P$. aeruginosa for their ability to invade into corneal epithelial cells of mice. After $1 \mathrm{~h}$ of invasion assay, there were no significant differences in the invasion among the isolates, but following a $3 \mathrm{~h}$ of infection, $P$. aeruginosa could be differentiated into invasive and cytotoxic strains and suggested that invasion was inversely correlated with cytotoxicity. Fleiszig et al., (1997), tested the invasion of $P$. aeruginosa strains on polarized MDCK cells and found low levels of invasion for both cytotoxic and invasive strains at $1 \mathrm{~h}$. However, at $3 \mathrm{~h}$ of infection, the percentage of associated bacteria invaded had increased approximately 4 to 9 -fold for the invasive isolates but decreased 13- to 15-fold for the cytotoxic isolates. In addition, the total number of associated bacteria for the cytotoxic isolates increased 6 to 8 -fold, while there was little to no increase for invasive isolates. However, in case of $P$. aeruginosa MCCB 123 used in the present study, even after $3 \mathrm{hrs}$ of incubation on both the monolayers (Hep-2 and HeLa), the strain was unable to adhere to or invade the cell line and thus the organism could be considered as a phenotype which was neither adhesive (cytotoxic) nor invasive agreeing with Zhu et al., (2006), who stated that there were phenotypes of $P$. aeruginosa that could be considered as neither cytotoxic nor invasive.

Common features of $P$. aeruginosa with high destructive capability on intestinal cell lines include high swimming motility, increased adhesiveness and the presence of exoU gene (Zaborina et al., 2006). The non-adhesive nature and the absence of exoU gene indicated the non-pathogenic nature of $P$. aeruginosa MCCB 123. However, the strain exhibited three types of motilities such as swimming, swarming and twitching motilities and proved to be a moderate biofilm producer with a $3.10 \pm 0.52$-fold increase in the optical density when compared to control (medium without inoculation) at Abs570. Biofilms exhibits increased resistance to antimicrobial agents 
due to the production of extracellular polymeric substances, presence of high concentration of $\beta$-lactamases, slower metabolic rates of the cells due to nutrient limitation and the presence of persistent cells (Deligianni et al., 2010). The characteristic property of bacterial biofilm is their remarkable resistance to antibiotics. The overall resistance depends upon the entire population of cells and therapy needs to be directed against a multicellular community (Stewart and Costerton, 2001).

Environmental isolates of P.aeruginosa are more susceptible to antibiotics when compared to their clinical counterparts (Ruiz et al., 2004). The antibiogram of $P$. aeruginosa MCCB 123 shows that the strain is sensitive to most of the antibiotics tested belonging to various classes, pencillins (carbenicillin, ticarcillin), cephems (ceftazidime, cefoperazone), carbapenems (imipenem), lipopeptides (colistin), aminoglycosides (gentamicin, amikacin, tobramycin, netilmicin), fluroquinolones (lomefloxacin, ofloxacin, norfloxacin), showed intermediate sensitivity to cefotaxime and ceftizoxime which belong to the class of cephems and is resistant to piperacillin which belongs to the class of penicillin. Antibiotics commonly used in the treatment of P.aeruginosa infection belong to the classes such as pencillins, cephalosporins, aminoglycoside, fluroquinolones, polymixin and carbapenems (Hancock and Speert, 2000).

The results of antibiogram of $P$. aeruginosa MCCB 123 suggested the possibility of antibiotic treatment as an effective method for eradication of its biofilm. The sensitivity of P.aeruginosa MCCB 123 to both ceftazidime and cefoperazone suggests that these can be used as a single agent against $P$. aeruginosa (Hancock and Speert, 2000). Gentamicin is usually effective against non-clinical environmental isolates of $P$. aeruginosa (Tripathy et al., 2007), while the pathogenic strains from clinical environment from cystic fibrosis patients were found to be resistant to this antibiotic (Deredjian et al., 2011). P. aeruginosa MCCB 123 showed sensitivity to gentamicin. Broad spectrum fluoroquinolones are used for the treatment of Pseudomonas keratitis (O'Brien et al., 1995 and Bower et al., 1996), fluoroquinolones and aminoglycosides for the treatment of endophthalmitis (Elder and Morlet, 2002). Fluroquinolones were also reported to be effective drugs for non-clinical (environmental isolates) of $P$. aeruginosa (Kaszab et al., 2011 and Silva et al., 2008). P. aeruginosa MCCB 123, being an environmental isolate, was sensitive to all the fluroquinolones tested. The organism also showed intermediate sensitivity to third generation cephalosporins such as cefotaxime and ceftazidime.

Environmental isolates of $P$. aeruginosa from compost is also reported to be resistant to third generation cephalosporins such as cefotaxime and ceftazidime (Kaszab et al., 2011). Further, the pathogenic clinical strains of $P$. aeruginosa were reported to be resistant to various classes of antibiotics belonging to the classes such as aminoglycosides, carbapenems, cephalosporins (Brown and Izundu, 2004). However, P. aeruginosa MCCB 123 is sensitive to the tested antibiotics belonging to the above said classes indicating that the organism is controllable by antibiotics.

The isolate was found to exhibit noncytotoxic characteristics based on invasion and adhesion assays on human epithelial monolayers. Its sensitivity to antibiotics indicated that it could be controllable by antibiotic therapy. The high level of proteolytic activity of the bacterium suggested its suitability in industrial applications. 


\section{Acknowledgement}

The authors acknowledge Cochin University of Science and Technology, Cochin, Kerala, for providing the financial support.

\section{References}

Atzel, B., Szoboszaly, S., Mikuska, Z., and Kriszt B. 2008. Comparison of phenotypic and genotypic methods for the detection of environmental isolates of Pseudomonas aeruginosa. Int. J. Hyg. Environ. Health. 211:143-155.

Baumann, P. and Schubert, R.H.W. 1984. Pseudomonadales. In: Krieg, N.R., and Holt, J.G. (Ed.), Bergy's Manual of Systematic Bacteriology, Williams and Wilkins, Baltimore.

Bower, K.S. and Kowalski, R.P., and Gordon, Y.J. 1996. Fluoroquinolones in the treatment of bacterial keratitis. Am. J. Ophthalmol., 121: 712-715.

Brown, P.D. and Izundu, A. 2004. Antibiotic resistance in clinical isolates of Pseudomonas aeruginosa in Jamaica. Pan. Am. J. Public Health, 16: 125-130.

Choy, M.H., Stapleton, F. Willcox, M.D.P. and Zhu, H. 2008. Comparison of virulence factors in Pseudomonas aeruginosa strains isolated from contact lens- and non-contact lens-related keratitis. J. Med. Microbiol., 57:15391546.

CLSI, 2007. Clinical and Laboratory Standards Institute, Performance standards for antimicrobial susceptibility testing. (17th Information supplement. Wayne, Pennsylvania).

Deligianni, E., Pattison, S., Berrar, D., Ternan, N.G., Haylock, R.W., Moore, J.E., Elborn, S.J., and Dooley, J.S.G. 2010. Pseudomonas aeruginosa cystic fibrosis isolates of similar RAPD genotype exhibit diversity in biofilm forming ability in vitro. $B M C$
Microbiol, 10: 38 .

Deredjian, A., Colinon, C., Brothier, E., Favre-Bonté, S., Cournoyer, B. and Nazaret, S. 2011. Antibiotic and metal resistance among hospital and outdoor strains of Pseudomonas aeruginosa. Res. Microbiol., 162: 689-700.

Elder, M.J. and Morlet, N. 2002. Endophthalmitis. Clin. Exp. Ophthalmol., 30: 394-398.

Fleiszig, S.M.J., Wiener-Kronish, J.P., Miyazaki, H., Vallas, V., Mostov, K.E., Kanada D, Sawa, T., Yen, T.S.B., and Frank, D.W. 1997. Pseudomonas aeruginosa-mediated cytotoxicity and invasion correlate with distinct genotypes at the loci encoding exoenzyme $S$. Inf. Immun., 65: 579-586.

Hancock REW and Speert DP, 2000. Antibiotic treatment in Pseudomonas aeruginosa. Mechanisms and impact of treatment. Drug Resist, Update, 3: 247255.

Hauser, A.R., Cobb, E., Bodi, M., Mariscal, D., Valles, J., Engel, J.N., and Rello, J. 2002. Type III protein secretion is associated with poor clinical outcomes in patients with ventilator associated pneumonia caused by Pseudomonas aeruginosa. Crit. Care. Med., 30: 521528.

Head, N.E., and Yu, H. 2004. Cross-Sectional Analysis of Clinical and Environmental Isolates of Pseudomonas aeruginosa: Biofilm Formation, Virulence, and Genome Diversity. Inf Immun., 72:133144.

Jose, D., Jayesh, P., Gopinath, P., Mohandas, A. and Singh, I.S.B. 2014. Potential application of $\beta-1,3$ glucanase from an environmental isolate of Pseudomonas aeruginosa MCCB 123 in fungal DNA extraction. Indian J. Exp. Biol., 52: 8996.

Jose, D., Jayesh, P., Gopinath, P., Mohandas, A. and Singh, I.S.B. 2017. A rapid two- 
step bacterial DNA extraction using LasA protease from Pseudomonas aeruginosa MCCB 123. Indian. J. Biotechnol., 16:425-434.

Jose, D., Mohandas, A. and Singh, I.S.B. 2017. Purification and characterization of a highly active LasB protease from Pseudomonas aeruginosa MCCB123. Indian J. Exp. Biol., 55:303-310.

Kaszab, E., Szoboszlay, S., Dobolyi, C., Háhn, J., Pék, N. and Kriszt, B. 2011. Antibiotic resistance profiles and virulence markers of Pseudomonas aeruginosa strains isolated from composts. Bioresour. Technol., 102:1543-1548.

Kiewitz, C. and Tummler, B. 2000. Sequence Diversity of Pseudomonas aeruginosa: Impact on Population Structure and Genome Evolution. J. Bacteriol, 182:3125-3135.

Lin, H-H., Huang, S-P., Teng, H-C., Ji, D-D., Chen, Y-S. and Chen Y-L. 2006. Presence of exoU gene of Pseudomonas aeruginosa is correlated with cytotoxicity in MDCK cells but not with colonization in BALB/c mice. J. Clin. Microbiol, 44: 4596-4597.

Lyczak, J.B., Cannon, C.L. and Pier, G.B. 2000. Establishment of Pseudomonas aeruginosa infection: lessons from a versatile opportunist. Microb. Infect, 2: 1051-1060.

O'Brien, T.P., Maguire, M.G., Fink, N.E., Alfonso, E. and McDonnell, P. 1995. Efficacy of oxoflacin vs. cefazolin and tobramycin in the therapy for bacterial keratisis. Arch. Opthalmol., 113:12571265.

Ortiz-Herrera, M., Gerónimo-Gallegos, A., Cuevas-Schacht, F., Pérez-Fernández, L. and Coria-Jiménez, R. 2004. RAPDPCR characterization of Pseudomonas aeruginosa strains obtained from cystic fibrosis patients. Salùd Publica. Mèxico, 46:149-157.
Palleroni, N.J. 1992. Introduction to the family pseudomonadaceae. In: Balows, H.G., Truper, M., Dworkin, W., Harder, A. and Schliefer, K. (Ed.), The Prokaryotes, NewYork, SpringerVerlag.

Prasad, K.N., Dhole, T.N. and Ayyagari, A. 1996. Adherence, invasion and cytotoxin assay of Campylobacter jejuni in HeLa and HEp-2 Cells. J. Diarrhoeal Dis. Res., 14:255-259.

Ruiz, L., Domínguez, M.A., Ruiz, N and Viñas M. 2004. Relation between clinical and environmental isolates of Pseudomonas aeruginosa in a hospital setting. Arch. Medical Res. 35:251-257.

Sambrook, J. and Russell, D.W. 2001. Molecular cloning: A Laboratory Manual. Cold Spring Harbor Laboratory Press, New York.

Schulert, G.S., Feltman, H., Rabin, S.D., Martin, C.G., Battle, S.E., Rello, J. and Hauser, A.R. 2003. Secretion of the toxin ExoU is a marker for highly virulent Pseudomonas aeruginosa isolates obtained from patients with hospital-accquired pneumonia. J. Inf. Dis., 188:1695-1706.

Senthil, R., Angel, K.J., Malathi, R. and Venkatesan, D. 2011. Isolation, identification and computational studies on Pseudomonas aeruginosa sp. strain MPC1 in tannery effluent. Bioinformation, 6:187-190.

Silva, M.E.Z., Filho, I.C., Endo, E.H., Nakamura, A.C., Ueda-Nakamura, T. and Filho, B.D.P. 2008. Characterisation of potential virulence markers in Pseudomonas aeruginosa isolated from drinking water. Antonie Van Leeuwenhoek, 93: 323-334.

Stepanovic, S., Vucovic, D., Dakic, I., Savic, B. and Svabic-Vlahovic, M. 2000. A modified microtiter-plate test for quantification of staphylococcal biofilm formation. J. Microbiol. Methods, 40: 
175-179.

Stewart, P.S. and Costerton, J.W. 2001. Antibiotic resistance of bacteria in biofilms. Lancet, 358:135-138.

Tripathy, S., Kumar, N., Mohanty, S., Samanta, M., Manda, R.N., and Maiti, N.K. 2007. Characterization of Pseudomonas aeruginosa isolated from freshwater culture systems. Microbiol. Res., 162:391-396.

Zaborina, O., kohler, J.E., Wang, Y., Bethel, C., Shevchenko, O., Wu, L., Turner, J.R. and Alverdy, J.C. 2006. Identification of multi-drug resistamt Pseudomonas aeruginosa clinical isolates that is highly disruptive to the intestinal epithelial barrier. Ann. Clin.
Microbiol. Antimicro., 5:14.

Zhu, H., Conibear, T.C.R., Bandara, R., Aliwarga, Y., Stapleton, F. and Willcox, M.D.P. 2006. Type III secretion systemassociated toxins, proteases, serotypes, and antibiotic resistance of Pseudomonas aeruginosa isolates associated with keratitis. Curr. Eye Res., 31: 297-306.

Zhu, H., Thuruthyil, S.J., and Willicox, M.D.P. 2002. Determination of quorum sensing signal molecules and virulence factors of Pseudomonas aeruginosa strains isolated from contact lensinduced microbial keratisis. J. Med. Microbiol., 51: 1603-1070.

\section{How to cite this article:}

Divya Jose, A. Mohandas and Bright Singh, I.S. 2018. A Non-Pathogenic Environmental Isolate of Pseudomonas aeruginosa MCCB 123 with Biotechnological Potential. Int.J.Curr.Microbiol.App.Sci. 7(01): 3060-3071. doi: https://doi.org/10.20546/ijcmas.2018.701.363 